Journal of Education and Vocational Research

Vol. 5, No. 1, pp. 13-16, Mar 2014 (ISSN 2221-2590)

\title{
Attitude of Private School Teachers towards Teacher Eligibility Test, India
}

\author{
*S. Murugan, P. Srinivasan \\ Tamil University, Thanjavur Tamilnadu, India \\ *mmurugan370@gmail.com
}

\begin{abstract}
Now-a-days the teacher education has some lack in quality. Because, the outcome of the quality teacher in teacher education colleges is low; some private management does not consider the quality of education and they depend on earning money. The present study investigates attitude of private school teachers towards Teacher Eligibility Test (TET). The tool of Attitude towards TET was constructed and standardized by the investigator. The data were collected from 327 private school teachers in Thanjavur District, India and simple random technique was used for the study. This study reveals that the attitude of private school teachers have high TET attitude and the private school teachers attitude is not significant with respect to gender, locality. Furthermore there is a significant difference in TET attitude between rural and urban area school teachers.
\end{abstract}

Keywords: TET, Teacher, India, Bed, Gender

\section{Introduction}

Education is a lifelong process; education is the cultivation of knowledge in the minds of living beings. The development and growth are all depend upon education that is provided. The central and state government is planning to develop the skill and quality manpower in development like medicine, science, technology and education etc. Education is a process by which people acquire knowledge, skills, habits values or attitude. Education is a dynamic force in the life of every individual, influencing his physical, mental, emotional, social and ethical development. Quality teacher's education is the need of the hour. Having a BEd degree will no longer be enough to become a school teacher. Candidates have to score minimum 60 percent in the test to qualify for teacher jobs at any private or government school. There is no bar on the number of attempts by an aspiring teacher for obtaining a CTET/STET certificate. Moreover, an aspirant can appear a second time to improve the score. The Validity Period of CTET qualifying certificate for appointment will be seven years from the date of declaration of its result for all categories. It is conducted by both Central government and State governments in India. Most states conduct their own TET.[1] The test is conducted in order fulfill and achieve Right to education goals. The test is mandatory for getting teaching jobs in government schools from Class 1 to Class 8. TET was introduced by the Government of India in order to improve standards in teaching. It was held for the first time in 2011.[2] For teachers already working, they are supposed to clear the exam in two years time..$^{[3]}$ A candidate has to score over 60 per cent to clear the eligibility test. ${ }^{[4]}$ The rationale for including the TET as a minimum qualification for a person to be eligible for appointment as a teacher is to bring national standards and benchmark of teacher quality in the recruitment process ${ }^{[5]}$; to induce teacher education institutions and students from these institutions to further improve their performance standards ${ }^{[5]}$; and to send a positive signal to all stakeholders that the Government lays special emphasis on teacher quality[5].

Teacher Eligibility Test: The implementation of the Right of Children to Free and compulsory Education (RTE) Act, 2009 requires the recruitment of a large number of teachers across the country in a time bound manner. In spite of the enormity of the task, it is desirable to ensure that quality requirement for recruitment of teachers is not diluted at any cost. It is therefore necessary to ensure that persons recruited as teachers posses the essential aptitude and ability to meet the challenges of teaching at the primary and upper primary level. In accordance with the provisions of sub-section(1) of section 23 of the Right of children to Free and Compulsory Education (RTE) Act, 2009, the National Council for Teacher Education (NCTE) has laid down the minimum qualifications for a person to be eligible for appointment as a teacher in class I to VII, vide its 
Notification dated August 23, 2010. One of the essential qualifications for a person to be eligible for appointment as a teacher in any of the schools referred to in clause (n) of section 2 of the RTE Act is that he/she should pass the Teacher Eligibility Test (TET) which will be conducted by the appropriate Government. The rationale for including the TET as a minimum qualification for a person to be eligible for appointment is as under:

- It would bring national standards and benchmark of teacher quality in the recruitment process;

- It would induce teacher education institutions and students for these institutions to further improve their performance standards;

- It would send a positive signal to all stakeholders that the government lays special emphasis on teacher quality.

The TET examination may be conducted by the suitable professional body designated by the appropriate Government for the purpose. It will be conducted in accordance with the Guidelines.

\section{Literature Review}

According to Kohlberg (1969), one of the main theories that provided information about attitude development was Kohlberg's Theory of Moral Development. This suggests that many adolescents may be at Moral Development Level 3. This level is often characterized by a need to please others (which in adolescence is likely to involve peer groups). A tentative conclusion is that pre-driver interventions involving other young people (e.g. peer-peer interventions) may prove successful. In general, a comprehensive understanding of those factors influencing the development of both the strength and direction of an individual's attitudes towards driving, riding and being a passenger is relevant to the development of appropriate types of predriver education interventions is required. Over a two-month period, the study team collected and reviewed 189 papers and contacted key researchers within national and international academic establishments. The initial development of a set of 23 research questions, linked to the study objectives, ensured that this process remained focused. Statistical analyses (e.g. correlations) are used to identify those items, which do/do not demonstrate consistency with the overall (summed) score across all items. Items with a correlation with the total score of less than 0.4 are typically removed from the set of items. A Likert Scale has a relatively small number of items (e.g. 10-15) with high discriminate validity. These findings are consistent with the general literature on factors influencing the effectiveness of persuasive communication. Moreover, these findings provide some support for the use of this literature to inform the development of a draft 'Good Practice Guide to Pre-driver Education'. Dhindsa \& Chung (2003) wrote about the attitude toward mathematics and the ages of 11-13 year olds. He states that these ages are particularly important in the development of a mathematical attitude. This is the time when negative attitudes become most noticeable.

Although he goes to say that the reason behind this is unclear. Possible reasons behind this are the greater prevalence of abstractions in mathematics material. In his research, using a Pearson correlation, he found a positive correlation between attitude and mathematics achievement. The correlation showed that the more positive the attitude, the higher the level of achievement was in the student Hannula. Kumar \& Morris(2005) Conducted the study on "predicting" scientific attitude of prospective Elementary Teachers: Role of Gender, Education level, Courses in Science, and Attitude towards Science and Mathematics" Multiple regression analysis of the relationship between prospective teachers' scientific attitude and Gender, Education Level (high school, college), Courses in science (Biology, Chemistry and Physics, Earth science, Astronomy, and Agriculture), Attitude Towards science, and Attitude Towards Mathematics is reported. Undergraduate elementary science students $(\mathrm{N}=176)$ in an urban in an urban doctoral. Level university in the United States participated in the study. Based on a regression model, Gender, and college chemistry and physics experiences added significant predictive accuracy to scientific attitude among prospective elementary teachers compared to the other variables. Kubiatko \& Vlckova (2010) investigated the Czech university students' attitudes towards ICT used in science education. They focused on differences of attitudes related to information and communication technologies among Czech university students. Students' attitudes were evaluated summative and with respect to gender, grade, and residence. The sample consisted of a total of 316 university students. The data analysis included factor analysis, ANCOVA, ANOVA, and t-test. The factor 
analysis yielded five dimensions: 1) Influence of ICT on teaching process, 2) Influence of ICT on human body and environment, 3) Using of ICT in teaching, 4) School and ICT, 5) ICT as didactic equipment. As a result, male students, sophomores, and students living in town showed more positive attitudes in comparison to other respective groups.

Need and Significance of the Study: The NCERT has decided to improve the quality in teacher education by conducting CTET and it recommends to state governments to conduct the eligibility test at state. The primary aim of CTET and TET are to make quality teacher education and reducing the jobless teachers. This study is used to know the attitude of the school teachers towards TET examination. So, the investigator of the study has taken the topic as "Attitude of Private School Teachers towards TET".

Research Questions of the Study: Following are the research questions of the study:

- Is the attitude of TET of school teachers high?

- Is there any significant difference in TET attitude between male and female school teachers?

- Is there any significant difference in TET attitude between rural and urban area school teachers?

Hypotheses of the Study: The investigator of the study formulated the following hypotheses:

- The attitude towards TET of school teachers is high.

- There is no significant difference in attitude towards TET between male and female school teachers.

- There is no significant difference in TET attitude between rural and urban area school teachers.

\section{Methodology}

For the present investigation the investigator adopted descriptive survey method. The sample consists of 327 working private school teachers studying in various private schools situated in Thanjavur District of Tamilnadu, India by using random sampling technique.

Tool Used: "Attitude towards TET (ATTET)" is used to measure the attitude of private school teachers towards TET which was constructed and standardized by the investigator. It is standardized by the investigator through pilot study. The face and content were found. The reliability of the tool is 0.72 which was found by test-retest method.

Table 1: Numbers and Mean scores of TET attitude of school teachers

\begin{tabular}{lll} 
Numbers & Mean & S.D \\
\hline 327 & 111.1 & 14.79 \\
\hline
\end{tabular}

Table 2: GroupWise Numbers, Mean SD and $t$ value of TET attitude between male and female school teachers

\begin{tabular}{llllll}
\hline Gender & Numbers & Mean & S.D & t-Value & Significance \\
\hline Male & 151 & 110.07 & 14.71 & & \\
Female & 176 & 111.98 & 14.30 & & Not Significant \\
\hline
\end{tabular}

Table 3: GroupWise Numbers, Mean SD and $t$ value of TET attitude between rural and urban area school teachers

\begin{tabular}{llllll}
\hline Locality & Numbers & Mean & S.D & t-Value & Significance \\
\hline Rural & 160 & 108.13 & 15.39 & \multirow{2}{*}{ Significant } \\
Urban & 167 & 113.94 & 13.04 & & \\
\hline
\end{tabular}




\section{Results}

Following are the major findings of the research study:

- The TET attitude of school teachers is high.

- There is no significant difference in TET attitude between male and female school teachers.

- There is a significant difference in TET attitude between rural and urban area school teachers.

\section{Present Scenario of TET and its Applicability}

- The Validity Period of CTET qualifying certificate for appointment will be seven years for all categories. The CTET is presently being conducted annually.

- There is no restriction on the number of attempts a person can take for acquiring a CTET Certificate. The CTET shall apply to schools of the Central Government (KVS, NVS, Tibetan Schools, etc) and schools under the administrative control of UT of Chandigarh and Andaman \& Nicobar Islands.

- CTET may also apply to the unaided private schools, who may exercise the option of considering the CTET.

- Schools owned and managed by the State Government/local bodies and aided schools shall consider the TET conducted by the State Government. However, a State Government can also consider the CTET if it decides not to conduct the State TET.

- A person who has qualified CTET may also appear again for improving his/her score.

\section{Conclusion}

The TET attitude of school teachers is high. It may due to the awareness of the TET examination. There is no significant difference in TET attitude between male and female school teachers. The gender does not exert any influence in TET attitude of school teachers. There is a significant difference in TET attitude between rural and urban area school teachers. It may due to the rural area teachers have low awareness with compare to urban area teachers.

Acknowledgement: This paper is part of the primary author's M.Phil research work. We thank anonymous reviewers for their constructive review of the manuscript, and we are very much grateful to the Editor for editorial revision, and the Editorial Assistant for the kind communication.

\section{References}

Dhindsa, H. S. \& Chung, G. (2003). Attitudes and achievement of Bruneian science students. Int J Sci Educ, 25, 907-922.

Kohlberg, L. (1969). Stage and Sequence: The Cognitive-Developmental Approach to Socialization. In The Handbook of Socialization Theory and Research, ed. David A. Goslin. Chicago: Rand McNally.

Kubiatko, M. \& Vlckova, K. (2010). The relationship between ICT use and science knowledge for Czech students: A secondary analysis of PISA 2006. International Journal of Science and Mathematics Education, 8(3), 523-543

Kumar, D. D. \& Morris, J. D. (2005). Predicting scientific understanding of prospective elementary teachers: Role of gender, education level, courses in science, and attitudes toward science and mathematics. Journal of Science Education and Technology, 14(4), 387-391.

http:// "Links to official State TET websites". 14 March 2014. Retrieved 14 March 2014.

http://articles.timesofindia.indiatimes.com/2011-07-30/nagpur/29832663_1_central-teacher-eligibility-

test-ctet-essential-aptitude-and-ability

http://www.telegraphindia.com/1110831/jsp/northeast/story_14444795.jsp

http://articles.timesofindia.indiatimes.com/2011-08-29/jaipur/29940836_1_successful-candidates-

examination-rajasthan-board

http://"CTET Official Website". 9 January 2014. Retrieved 8 February 2014. 